\title{
Abordaje Anestésico Multimodal en cirugía de tórax, con bloqueo del plano del erector espinal
}

\author{
Schiavon V. ${ }^{1}$ \\ 1 Hospital Regional Dr. Ramón Carrillo, Santiago del Estero, Argentina.
}

Introducción: Los procedimientos torácicos llevan aparejado complicaciones, especialmente en el compromiso de la mecánica pulmonar del paciente afectado, lo que hace imperativo lograr un control optimo del dolor, convirtiendo al manejo anestésico multimodal en un pilar importante en el manejo de esta entidad.

Descripción del caso: Un paciente masculino, de 26 años, $63 \mathrm{~kg}$, ASA II, programado para toracotomía axilar vertical amplia. Como antecedentes; colocación de tubo pleural 2 meses atrás, por derrame pleural paraneumónico, con mala evolución, complicado con empiema tabicado, en tratamiento antibiótico. Al examen físico; Vía Aérea, buena apertura bucal, Mallampati 2; Ap Resp: abolición de MV en base pulmonar derecha con roncus aislados en campo pulmonar derecho. Sat 02 97\% ambiente; Examen de columna sin particularidades. Exámenes Complementarios: Laboratorio con leve leucocitosis; Rx tórax opacidad difusa homogénea, con borramiento de ángulos costodiafragmáticos derecho.

Previo a la cirugía, se realiza bloqueo del plano del erector espinal, a nivel de T5 y T6 guiado por ecografía, en posición sentado, con aguja estéril $22 \mathrm{G}$ de $50 \mathrm{~mm}$, con técnicas de asepsia y antisepsia, se instauran en total $30 \mathrm{~mL}$ de bupivacaina isobárica al $0,25 \%$.

Luego se procede a realizar anestesia general. Premedicación: fentanilo $150 \mathrm{mcg}$, midazolam $5 \mathrm{mg}$. Inducción Propofol $80 \mathrm{mg}$, atracurio $30 \mathrm{mg}$. IOT sin complicaciones. Mantenimiento: Sevoflurane $1 \%$ Remifentanilo $0.3 \mathrm{mcg} / \mathrm{kg} / \mathrm{min}$. Medicación: Ketamina $20 \mathrm{mg}$, Diclofenac $75 \mathrm{mg}$, Ranitidina $50 \mathrm{mg}$, Metoclopramida $10 \mathrm{mg}$, Dexametasona $8 \mathrm{mg}$.

Duración de la cirugía 3 h. Se procede a la extubación del paciente, sin complicaciones. En unidad de recuperación el paciente presenta dolor (EVA) 2/10, se indica plan analgésico con tramadol $50 \mathrm{mg} / 6 \mathrm{~h}$. El paciente pasa a sala de cuidados intermedios.

Comentarios: La evaluación postoperatoria del paciente dentro de las primeras $24 \mathrm{~h}$ fue favorable, con leve dolor a la deambulación y movilización del tubo pleural y drenajes.

Discusión: Actualmente, se ha descripto la utilización del bloqueo del plano del erector espinal con fines anestésicos, debido a su alcance anatómico, y la visualización de los mismos mediante ecografía, sin embargo no hay estudios que comparen la eficacia o la seguridad de este bloqueo, con los que habitualmente se emplean para cirugía de tórax como la colocación de catéter epidural.

https://doi.org/10.25237/congresoclasa2019.54 